wide development of these schemes could be seen as the result of diverse factors: the move within psychiatry towards community care; the growth in the number of health centres; the development of general practitioner vocational training schemes. Moreover, in spite of the uncoordinated nature of the development of this pattern of service, three clearly distinguishable patterns of working collaboration could be identified: a consultation pattern; a shifted out-patient pattern; and a liaison-attachment team pattern. In general, psychiatrists seemed to be enthusiastic about the benefits to be derived from this type of service, both in terms of clinical care for patients and in opportunities provided for education and collaboration with general practitioners.

Speakers from the World Health Organisation, and the National Institute of Mental Health in the United States, gave their views of the policies of the above organizations in relation to the theme of the conference, and a number of European psychiatrists commented on the importance of the development of psychiatry in primary care settings. Professor J. Cooper commented: 'Our [general] practice system is . . . simple to describe, it is comprehensive, it is universally available and it must be fairly easy to study. Our overseas friends, I think, could be forgiven if they wonder why, when we have all these virtues, we do such a small amount of research into the British system.'

The final session, entitled 'Future Research and Policy', consisted of two papers, one given by Sir Desmond Pond, Chief Scientist at the DHSS, and the other presented by Dr Donald Irvine, the Chairman of the Council of the Royal College of General Practitioners. Sir Desmond highlighted the importance to the Department of research and development in the area of clinical management for patients with mental disorders, and made a 'plea for more involvement of researchers in the development of the results of their findings'. The thrust of Dr Irvine's contribution concerned the 'new realization and acceptance of [his] profession's responsibilities and [their] determination as an important discipline in British medicine to get to grips decisively with [their] outstanding problem of quality control'. Or, as Professor Shepherd remarked in his summing up, so far as future research on mental health in primary care settings is concerned, 'something has to be done to bring in general practitioners on a more active basis. The whole question of how that should be done is, I think, a policy matter.'

The speakers' presentations were followed by lengthy and, at times, vigorous discussions from both the platform and the floor of the hall. A full record of the proceedings will become available in published form in due course.

\section{Acknowledgement}

I am grateful to my colleagues in the General Practice Research Unit who helped in the preparation of this conference report.

\title{
British Psychosocial Oncology Group
}

A meeting was held in November 1983 at King's College Hospital on the psychosocial aspects of cancer. This meeting attracted a large number of psychiatrists, physicians, social workers, psychologists and nurses who were involved in research and clinical care in the psychosocial aspects of cancer. The conference was extremely successful and it was felt at that time by the participants that it would be useful to establish a British group whose focus of interest would be on the psychological, psychiatric and social aspects of oncology. A committee has now been established for this British Psychosocial Oncology Group under the chairmanship of Dr Stephen Greer at King's College Hospital. It is hoped that this group will be able to organize an annual conference and will be able to produce a newsletter to be sent to the members informing them of recent developments in the field. In the future it may be possible to organize specific training and workshops for interested people. The group also hopes to be able to maintain a register of members with details of their research interests so it can provide a useful central information point for those involved in or embarking upon, research and/or clinical practice in the area of psychosocial oncology.

The group is hoping to attract a wide variety of professional people who are clinically involved in caring for cancer patients and if there are any readers of this journal who would be interested in joining or obtaining further details they should contact the secretary, Dr M. Watson, Faith Courtauld Unit, King's College School of Medicine and Dentistry, The Rayne Institute. 123 Coldharbour Lane, London SE5 9MU.

\section{Psychiatrists Working in Primary Care Settings}

A recent survey indicates that one in five consultants in England and Wales do some work in the Primary Care Setting. It has been suggested that those who spend part of their time in such settings welcome an opportunity of meeting together and comparing styles of practice and other aspects of their work. The Executive Committee of the Section for Social and Community Psychiatry therefore suggested that an informal sub-group could be set up if sufficient members are interested. Dr A. R. K. Mitchell, 40 Top Cliffe Way, Cambridge CB1 4SH, has offered to work as convener of this group and any member who is interested in joining should write to him. 